\title{
The more the merrier: \\ The Cardueae Radiations Group and the power of team work.
}

\author{
Alfonso Susanna' (10) \\ 'Botanic Institute of Barcelona (IBB, CSIC- Ajuntament de Barcelona), Pg. del Migdia s.n., 08038 Barcelona, asusanna@ibb.csic.es \\ DOI: http://dx.doi.org/ | 0.53875/capitulum.01.1.01
}

Keywords: Jurinea, Saussurea, subtribal classification, target-enrichment.

The systematics of the Cardueae Cass. has been a headache for centuries. Thistles are one of the largest tribes of the Compositae, and the diversity of forms, habits, and floral structures they hold has made it very difficult to obtain a satisfactory subtribal classification. Since Cassini's first attempts (Cassini, 1819), proposals have been many, none of them unanimously accepted: the problems were subdued, but they reappeared; a well-known story reviewed in depth by Susanna et al. (1995). The latest classification proposed by Susanna \& Garcia-Jacas (2007, 2009) into five subtribes (Cardopatinae, Carlininae, Echinopsinae, Carduinae and Centaureinae) was still, in the authors' words, a compromise solution.

In addition to the difficulties of subtribal classification, one of the problems of the Cardueae has been the megagenera of the tribe: Cousinia Cass. (600 spp.), Cirsium Mill. (400 spp.), Jurinea Cass. (200 spp), Saussurea DC. (400 spp.) and Centaurea L. (250 spp.). The study of any of them is fraught with difficulties: from the sampling, which must be exhaustive, to the methodology used. Our previous experiences of analyzing large genera with traditional sequencing (Cousinia, cf. López-Vinyallonga et al. 2009; Centaurea, cf. Hilpold et al., 20/4) had been disappointing. Mandel's work fine-tuning the target-enrichment method for Compositae (Mandel et al., 20l4) made us think that we finally had a tool capable of tackling studies that until now seemed utopian. We needed a better tool, and the target-enrichment sequencing methodology seemed a great opportunity to us.
In view of the arrival of better and very promising methods, from the Botanical Institute of Barcelona we decided in 2017 to undertake the study of two of the greatest radiations of the tribe: the genera Saussurea and Jurinea, a poorly known and worse defined group with a spectacular radiation in the mountains of East Asia. The first challenge was sampling. Most of the Saussurea species are found in the Qinghai-Tibetan Plateau, the Himalayas and especially in the Hengduan Mountains. Jurinea species, on the other hand, are located somewhat more to the northwest, in the Tian Shan, with secondary nuclei in the Caucasus and the IranoTuranian plateau. Altogether, it is an immense region, difficult to access and that poses logistical problems that cannot be solved in the four-year course of a research project. This is the basic point of this article: the creation of an international working group to solve the problem of sampling. The Cardueae Radiations group was born, made up of scientists from China, Korea, France, Iran, Japan, Russia, Spain, and the USA. The group was formed by researchers specialized in the genera of study from all regions, with the main goal of achieving a large sample; and a second goal: each participant in their area would contribute taxonomic knowledge of the species that would be included in the project.

The first step of the project consisted in verifying that the target-enrichment technique offered us the results we expected. Mandel (20/4) had already shown that the probes designed for the Compositae gave results in the Cardueae but on a minimal 


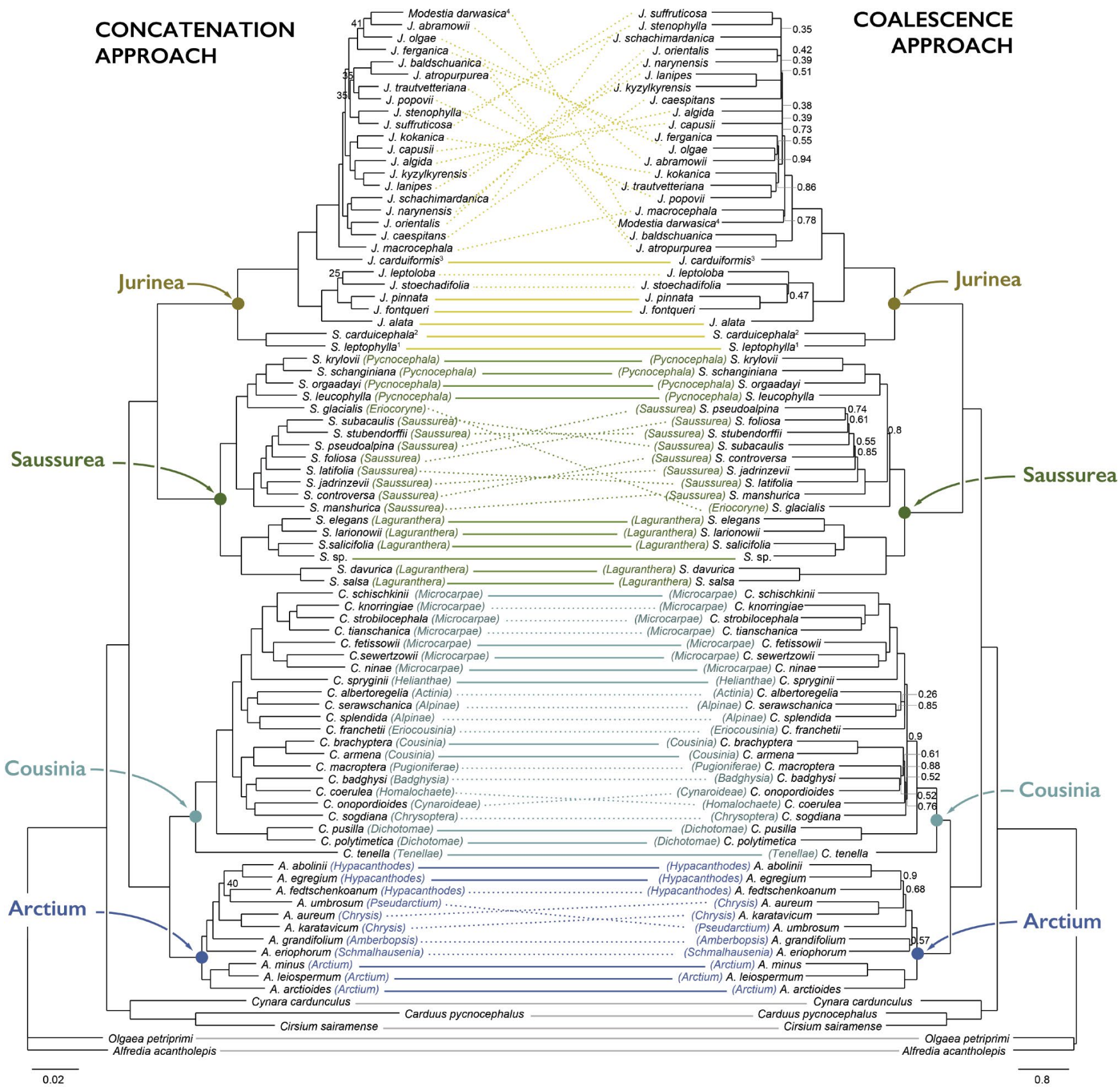

Figure I. Phylogenetic trees inferred from the concatenation approach and the coalescence approaches, on a sample of the largest three genera of tribe Cardueae. Continuous lines linking the species represent congruent positions between both trees, dashed lines represent incongruent positions. Sections are indicated between brackets for each species. From Herrando-Moraira et al. (20|8).

sample. We designed a sample that included species of the radiations targeted by the project. The result of this study (Herrando-Moraira et al., 20।8) showed that the technique worked; the results were promising. We also took advantage of the preliminary study to fine-tune the technique and test different data processing methods (pipelines) and analysis methods (coalescence and concatenation;
Figure I). After this success and after verifying that the technique worked, the next step was to try to solve two problems prior to the specific studies of Jurinea and Saussurea.

One of the problems was the classification of Jurinea and Saussurea in their own subtribe. The possibility of defining a new subtribe Saussureinae 
was informally suggested by Susanna \& Garcia-Jacas (2007, 2009) but inconsistencies in the molecular results resulted in an entanglement of Jurinea, Saussurea and Cousinia (Susanna et al., 2006; Barres et al., 2013). Thereafter, we gathered a sample of I40 species that represented all the taxonomic groups defined in the Cardueae, both the formal ones (the five classical subtribes) plus the informal groups of Susanna \& Garcia-Jacas (2009). This work was a complete success and we finally obtained a natural classification of the tribe, a classification that matched exactly what could be deduced from the morphology (Herrando-Moraira et al., 2019).
The proposed classification (Figure 2; Figure 3) can be considered revolutionary and we have gone from recognizing five sub-tribes to recognizing twelve, six of them new: Carlininae, Cardopatiinae, Echinopsinae, Dipterocominae (Figure 5), Xerantheminae, Berardiinae, Staehelininae, Onopordinae, Carduinae, Arctiinae, Saussureinae (Figure 6) and Centaureinae (Figure 7). An important conclusion of the study was that previous problems in classification are due to the use of plastid markers (e.g., Barres et al., 20l3), and an old hybridization at the base of ArctiumCousinia-Saussurea-Jurinea makes plastid and nuclear markers give contradictory results.

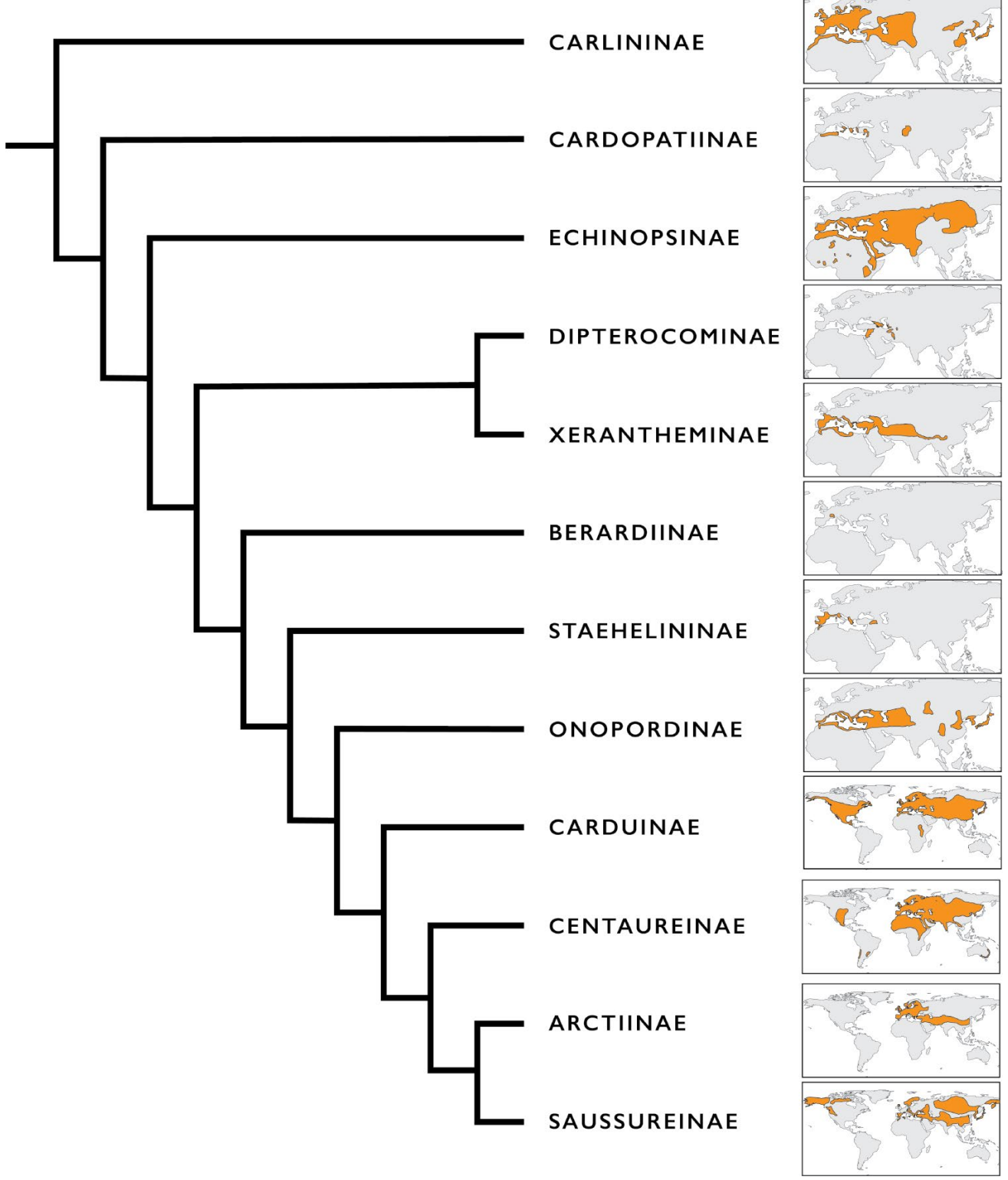

Figure 2. Condensed phylogenetic tree resulting from the analysis of Herrando-Moraira et al. (2019) showing the new classification of tribe Cardueae in twelve subtribes and their geographic distributions.. 


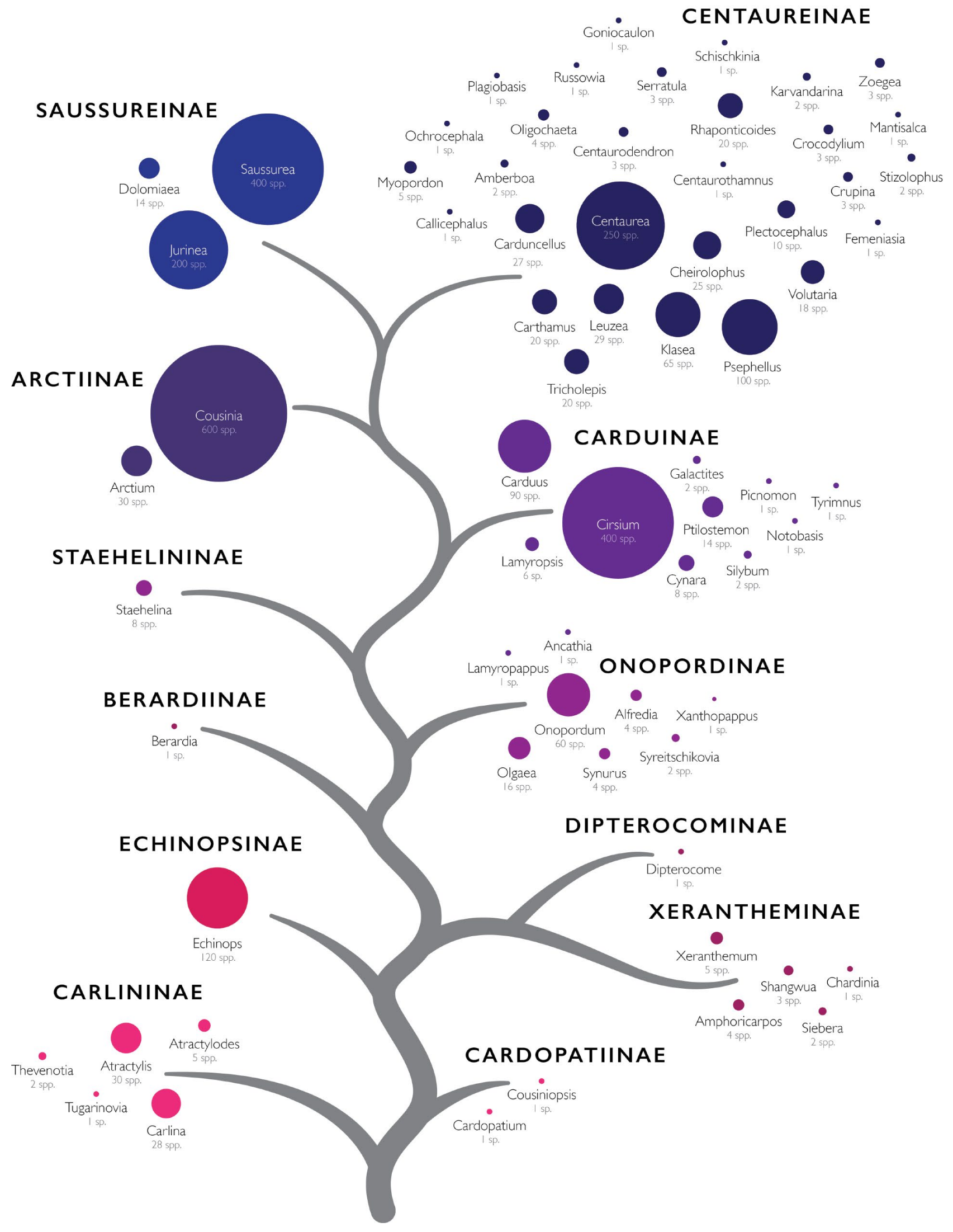

Figure 3. Diagram showing the subtribes and genera of Cardueae distributed along a tree. The size of the circles is proportional to the number of species in each genus. 


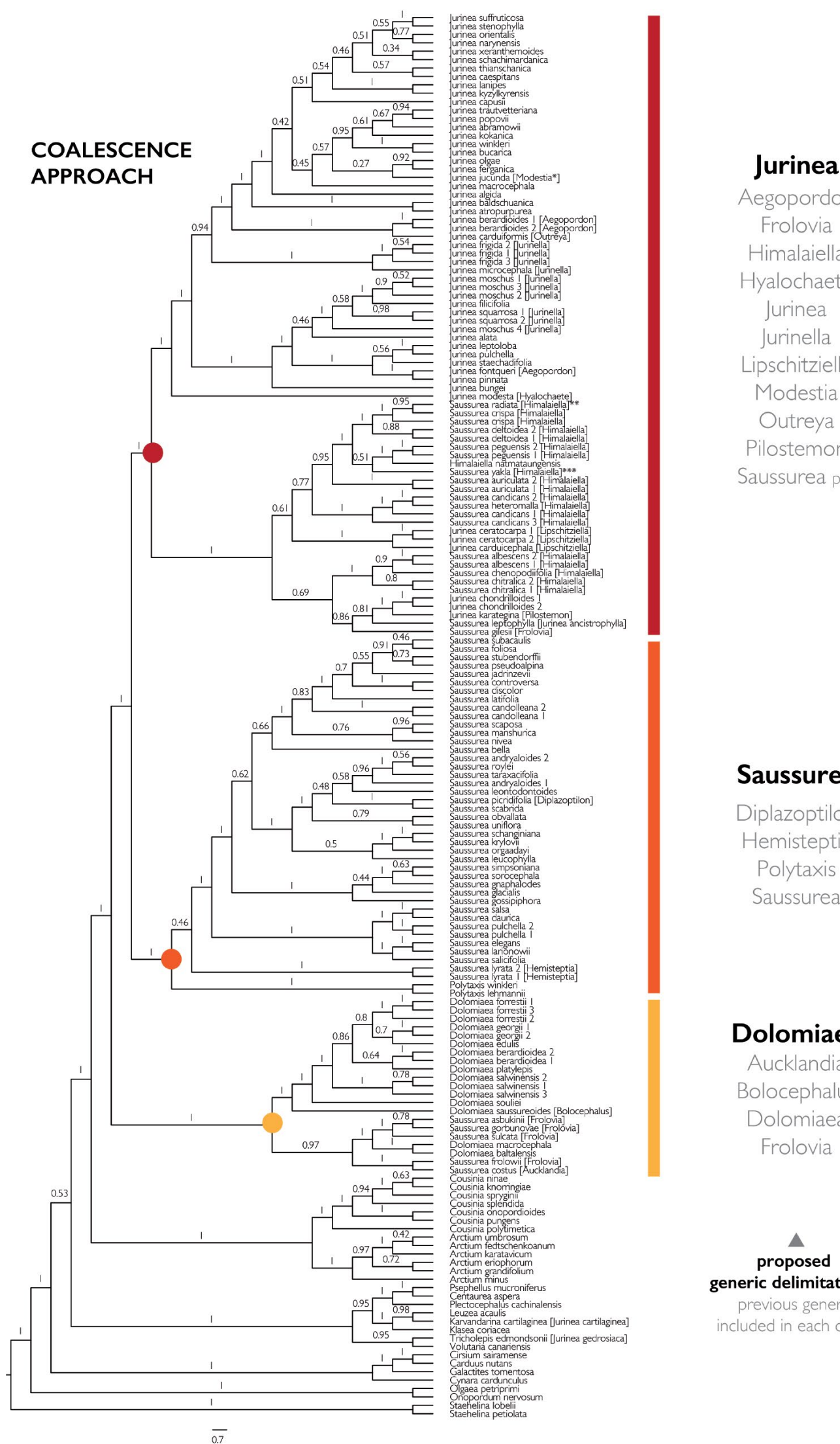

Aegopordon

Frolovia

Himalaiella

Hyalochaete

Jurinea

Jurinella

Lipschitziella

Modestia

Outreya

Pilostemon

Saussurea p.p.

\section{Saussurea}

Diplazoptilon

Hemisteptia

Polytaxis

Saussurea

\section{Dolomiaea}

Aucklandia

Bolocephalus

Dolomiaea

Frolovia

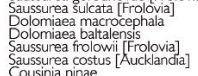

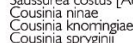

Cousina spyegini
Cousinin splendiida
Cousinia onopordioides

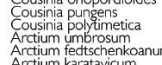

Arctium unmbrosum
Arctium katshenkoanum
karatavicum

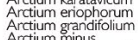

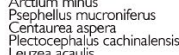

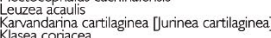

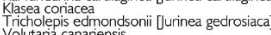

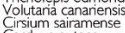

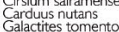

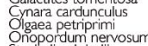

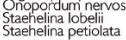

Figure 4. Phylogenetic tree of subtribe Saussureinae showing how all the genera described in the subtribe should be classified in only three. From Herrando-Moraira et al. (2020). 


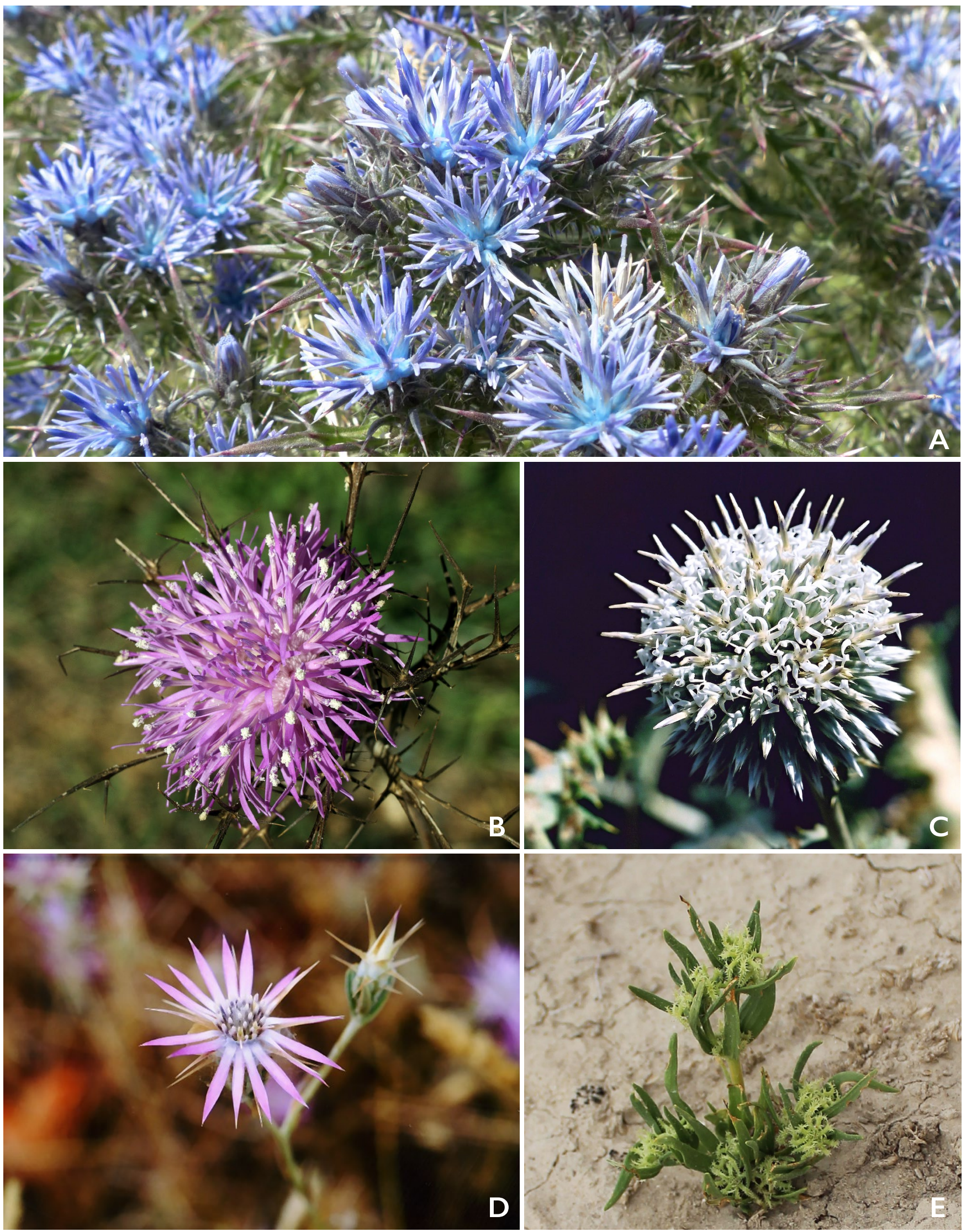

Figure 5. Diversity across the Cardueae. A. Cardopatium corymbosum Pers. (Cardopatiinae). B. Carlina comosa (Spreng.) Greuter (Carlininae). C. Echinops spinosissimus Freyn (Echinopsinae). D. Siebera pungens (Lam.) J.Gay ex DC. (Xerantheminae). E. Dipterocome pusilla Fisch. \& C.A.Mey. (Dipterocominae). Photos: A-D, A. Susanna; E, A. Pavlenko. 
The second problem (a vexing one) was posed by the generic delimitation of Saussurea and Jurinea. We could not undertake a study of a genus without knowing its exact limits, and this was not the case. To give an example of the complexity of the group, the Flora of China (Shi \& Raab-Straube, 20I I) recognizes I I genera in the Jurinea-Saussurea complex, while Susanna \& Garcia-Jacas (2009) only accepted three, out of the ca. 20 genera described in the complex (Susanna et al., 2006). We designed a sample that for the first time gathered representatives of every small genus described in the Saussureinae and we applied the target-enrichment procedure. The result was unambiguous (Figure 4): all the variability of the Saussureinae can be packed in only three genera (Herrando-Moraira et al., 2020).
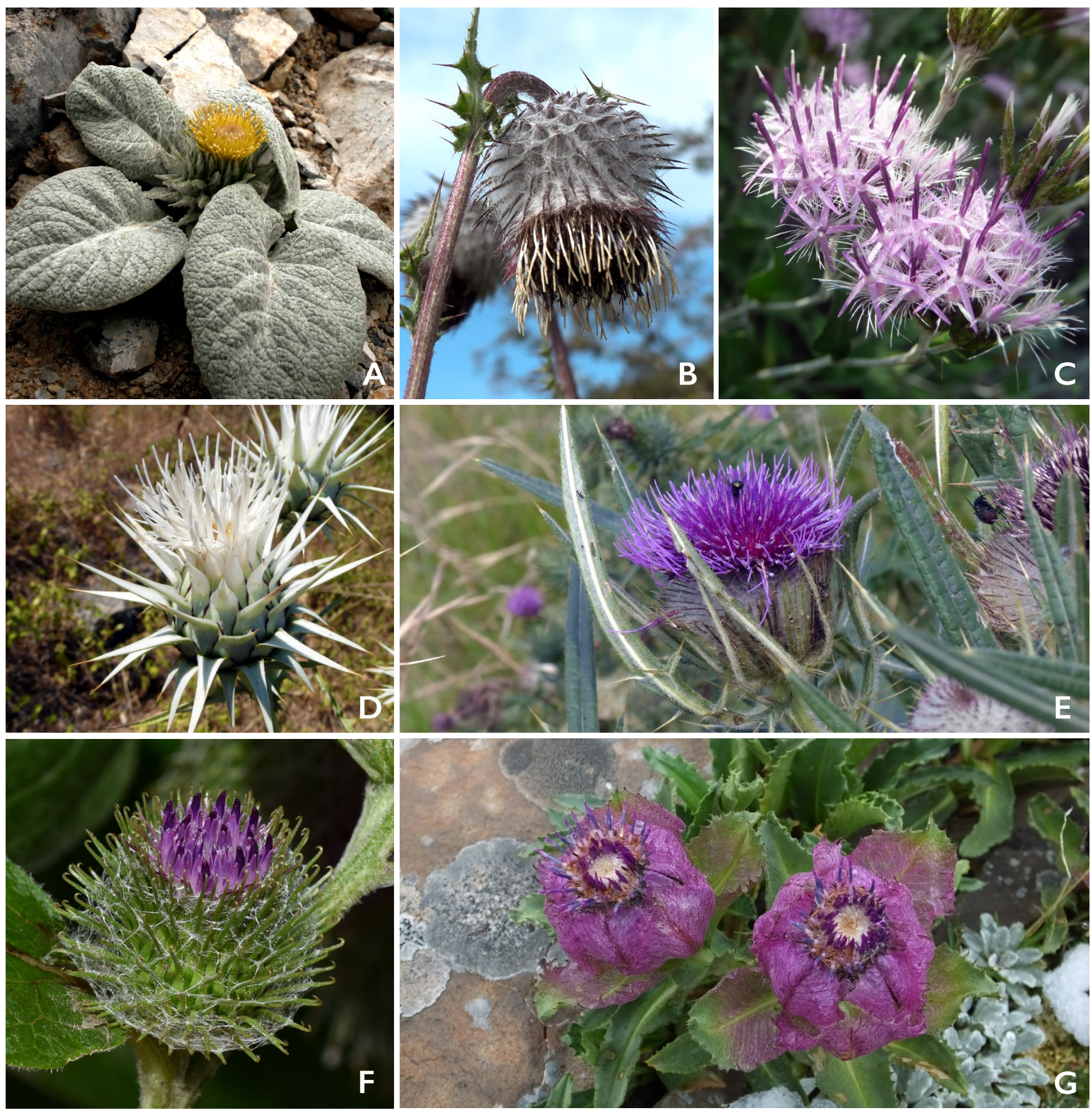

Figure 6. Diversity across the Cardueae (cont.). A. Berardia subacaulis Vill. (Berardiinae). B. Synurus deltoides (Aiton) Nakai (Onopordinae). C. Staehelina petiolata (L.) Hilliard \& B.L.Burtt (Staehelininae). D. Cynara baetica (Spreng.) Pau (Carduinae). E. Cirsium eriophorum Scop. (Carduinae). F. Arctium lappa L. (Arctiinae). G. Saussurea bracteata Decne. (Saussureinae). Photos: A, C. Roquet; B,D-E, A. Susanna; F. M. Bonifacino; G. J. López-Pujol. 

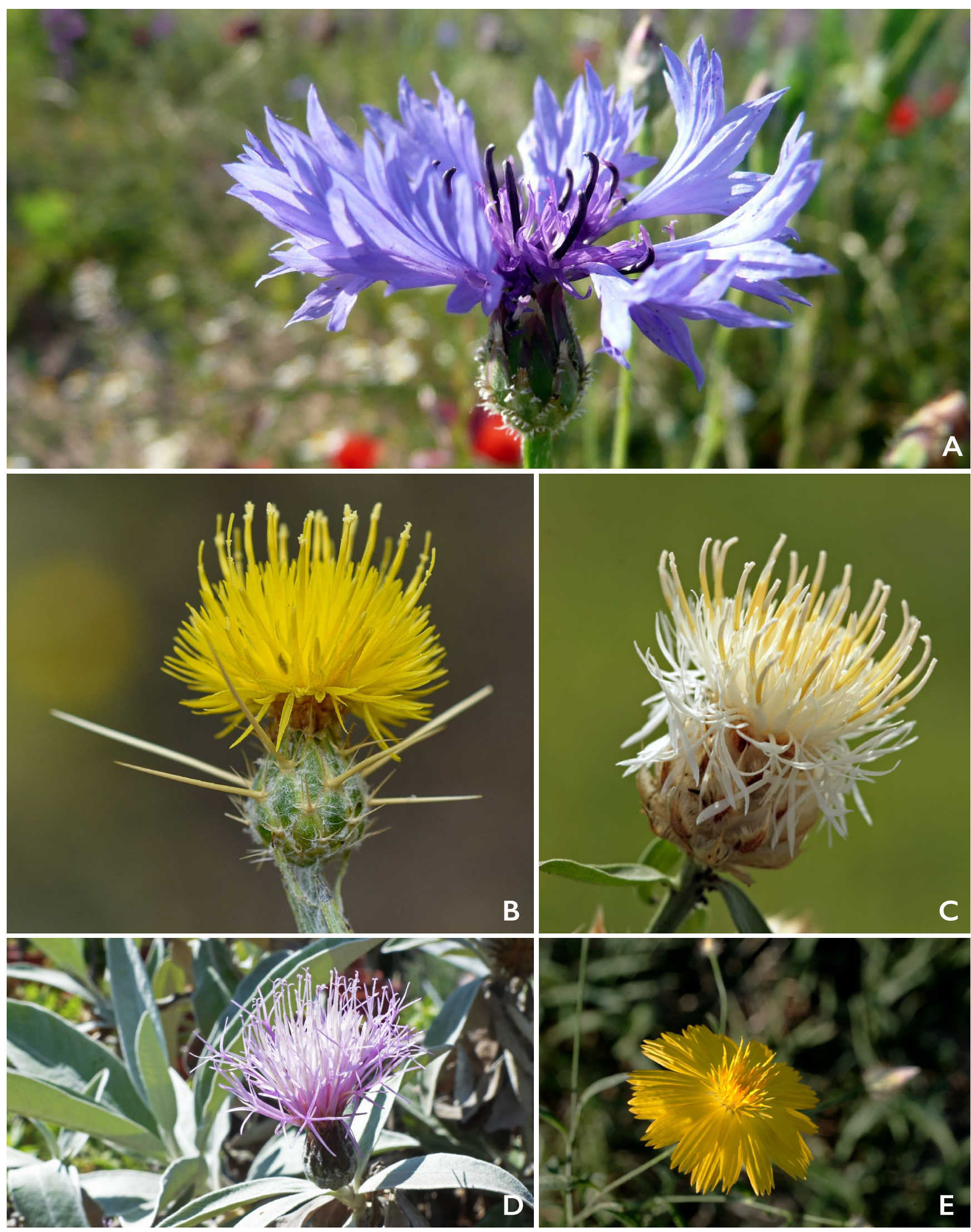

Figure 7. Diversity across the Cardueae (cont.). Centaureinae. A. Centaurea cyanus L. B. Centaurea solstitialis L. C. Centaurea princeps Boiss \& Heldr. D. Centaurothamnus maximus (Forssk.)Wagenitz \& Dittrich. E. Zoegea mianensis Bunge ex Boiss. Photos: A, C-E, A. Susanna; B, M. Bonifacino. 
After these three preliminary steps, the way is clear to study in depth the radiations of the great genera of the tribe and in fact we have already finished the study of the first, that of the Jurinea. According to our results, the radiation of Jurinea in the IranoTuranian region was mainly triggered by changes in climate (aridification and cooling) that followed the transition from Pliocene to Pleistocene.

None of these achievements, which have revolutionized our concept of the tribe and solved centuries-old taxonomic problems, would have been possible without the creation of the Cardueae Radiations Group. The more the merrier was a theme of the late Vicki Funk, and it was a guiding principle that she followed when creating the TICA. We have our own version in Spanish: más seremos, más reiremos (the more we will be, the more we will laugh), which demonstrates that this is old wisdom. From here I encourage our colleagues to follow suit; it works.

\section{ACKNOWLEDGMENTS}

The author gratefully thanks the members of the group for taking part in this venture: J. A. Calleja, P. Carnicero, Y.-S. Chen, K. Fujikawa, M. GalbanyCasals, N. Garcia-Jacas, H.-T- Im, S.-C. Kim, J.-Q. Liu, J. López-Alvarado, J. López-Pujol, J. Mandel, S. Massó, I. Mehregan, N. Montes-Moreno, C. Roquet, L. Sáez, A. Sennikov, R. Vilatersana and L.-S. Xu. Special thanks to $M$. Bonifacino for inspiring this note and his invaluable and skilled graphic design of the figures; and to J. Mandel for reviewing the text.

\section{LITERATURE CITED}

Barres, L., Sanmartín, I., Anderson, C.L., Susanna, A., Buerki, S., Galbany-Casals, M. \& Vilatersana, R. 2013. Reconstructing the evolution and biogeographic history of tribe Cardueae (Compositae). Amer. J. Bot. 100: 867-882.

Cassini, H. 1819. [Different articles]. Dictionnaire de Sciences Naturelles. Paris. In R. King and H. W. Dawson [eds., 1975], Cassini on Compositae. New York: Oriole.
Herrando-Moraira, S., The Cardueae Radiations Group (Calleja, J.A., Carnicero-Campmany, P., Fujikawa, K., Galbany-Casals, M., Garcia-Jacas, N., Im, H.-T., Kim, S.C., Liu, J.-Q., López-Alvarado, J., López-Pujol, J., Mandel, J.R., Massó, S., Mehregan, I., Montes-Moreno, N., Pyak, E., Roquet, C., Sáez, L., Sennikov, A., Susanna, A. \& Vilatersana, R. 2018. Exploring data processing strategies in NGS target enrichment to disentangle radiations in the tribe Cardueae (Compositae). Molec. Phylogen. Evol. 128: 69-87. https://doi.org/I 0.1016/j.ympev.20 18.07.012

Herrando-Moraira, S., The Cardueae Radiations Group (Calleja, J.A., Galbany-Casals, M., Garcia-Jacas, N., Liu, J.-Q., López-Alvarado, J., López-Pujol, J., Mandel, J.R., Massó, S., Montes-Moreno, N., Roquet, C., Sáez, L., Sennikov, A., Susanna, A. \& Vilatersana, R. 2019. Nuclear and plastid DNA phylogeny of tribe Cardueae (Compositae) with Hyb-Seq data: A new subtribal classification and a temporal diversification framework. Molec. Phylogen. Evol. I37: 31 3-332. https://doi.org/ | 0. 10 | 6/j.ympev.20 | 9.05.00 |

Herrando-Moraira, S., The Cardueae Radiations Group (Calleja, J.A., Chen, Y.S., Fujikawa, K., Galbany-Casals, M., Garcia-Jacas, N., Kim, S.C., Liu, J.Q., López-Alvarado, J., López-Pujol, J., Mandel, J.R., Mehregan, I., Roquet, C., Sennikov, A., Susanna, A., Vilatersana, R. \& Xu, L.S. 2020. Generic boundaries in subtribe Saussureinae (Compositae: Cardueae): Insights from Hyb-Seq data. Taxon 69: 694-7I 4.

Hilpold, A., Garcia-Jacas, N., Vilatersana, R. \& Susanna, A. 2014. Taxonomical and nomenclatural notes on Centaurea: A proposal of classification, a description of new sections and subsections, and a species list of the redefined section Centaurea. Collect. Bot. (Barcelona) 33: I-29.

López-Vinyallonga, S., Mehregan, I., Garcia-Jacas, N., Tscherneva, O., Susanna, A. \& Kadereit, J.W. 2009. Phylogeny and evolution of the Arctium-Cousinia complex (Compositae, Cardueae-Carduinae). Taxon 58: |53-|7|. https://doi.org/l 0.1002/tax.581016

Mandel, J.R., Dikow, R.B., Funk, V.A., Masalia, R.R., Staton, S.E., Kozik, A., Michelmore, R.W., Rieseberg, L.H. \& Burke, J.M. 20I4. A target enrichment method for gathering phylogenetic information from hundreds of loci: an example from the Compositae. Appl. PI. Sci. 2: I 300085. https:// doi.org/ | 0.3732/apps. I 300085

Shi, Z. \& Raab-Straube, E. von. 20I I. Saussurea group. Pp. 42-149 in: Wu, Z.Y., Raven, P.H. \& Hong, D.Y. (eds.), Flora of China, vol. 20-2I (Asteraceae). Beijing: Science Press; St Louis: Missouri Botanical Garden Press. 
Susanna, A. \& Garcia-Jacas, N. 2007. Tribe Cardueae Cass. (I819). Pp. 123-| 46 in: Kadereit, J.W. \& Jeffrey, C. (eds.), The families and genera of vascular plants, vol. 8. Berlin \& Heidelberg: Springer.

Susanna, A. \& Garcia-Jacas, N. 2009. Cardueae (Carduoideae). Pp. 293-313 in: Funk, V.A., Susanna, A., Stuessy, T.F. \& Bayer, R.J. (eds.), Systematics, evolution, and biogeography of Compositae. Vienna: International Association for Plant Taxonomy. https://doi.org/ / 0.31 20/0024-9637-56.3.209
Susanna, A., Garcia-Jacas, N., Hidalgo, O., Vilatersana, R. \& Garnatje, T. 2006. The Cardueae (Compositae) revisited: Insights from ITS, trnL-trnF, and matK nuclear and chloroplast DNA analysis. Ann. Missouri Bot. Gard. 93: I50-17|. https://doi. org/I0.341 7/0026-6493(2006)93[I 50:TCCRIF]2.0.CO;2

Susanna, A., Garcia-Jacas, N., Soltis, D.E. and Soltis, P.S. 1995. Phylogenetic relationships in tribe Cardueae (Asteraceae) based on ITS sequences. Amer. J. Bot. 82: I056-1068. 